\title{
EFEKTIVITAS SALEP KOMBINASI EKSTRAK DAUN BANGUN-BANGUN (Coleus amboinicus Lour.) DAN DAUN KELAPA SAWIT (Elaeis guineensis Jacq.) SEBAGAI OBAT LUKA SAYAT
}

\author{
Rika Puspita Sari, Nina Irmayanti, Evi Deviana Gultom, Palas Tarigan \\ Fakultas Farmasi Institut Kesehatan Deli Husada Deli Tua \\ e-mail :rikapuspitasaritambunan@gmail.com
}

\begin{abstract}
Bangun-bangun leaves and palm leaves contain various secondary metabolites such as tannins, alkaloids and flavonoids which can healing wound. The aim of this study was to determine the effect of ointment combination of ethanol extract of leaves of bangun- bangun (Coleus amboinicus Lour.) And ethanol extract of palm leaves (Elaeis guineensis Jacq.) In healing wound. The bangun- bangun leaves and the palm leaves are separated from the petiole and then dried in a drying cupboard so that it becomes a simplisia. Simplisia is extracted by maceration method then evaporated with a rotary evaporator and evaporated again on a water bathto produce a thick extract. Thick extracts from the leaves of bangunbangun and palm leaves are then formulated into ointment preparations with varying concentrations. Each rabbit was shaved on its back then cleaned with $70 \%$ alcohol. Furthermore, rabbits were anesthetized using $0.5 \mathrm{ml}$ Lidocain $H C L$ as much as $0.5 \mathrm{ml}$ subcutaneously. Next mark the part that will be injured with a diameter of $2 \mathrm{~cm}$, by lifting the rabbit skin using tweezers and then made a wound using surgical scissors that have been sterilized first with $70 \%$ alcohol. Wound diameter measurements showed that all treatment groups from day 1 to day 23 experienced changes in wound diameter. The combination ointment of ethanol extract of leaves wake-up (EEDB) $10 \%$ and ethanol extract of palm oil leaves (EEDKS) $10 \%$ have a more effective effect in wound healing than singledose.
\end{abstract}

Key words: Bangun-bangun leaves, palm leaves,ointment, wounds

\section{PENDAHULUAN}

Luka merupakan suatu keadaan terputusnya kontinuitas stuktur jaringan tubuh dari kondisi normal yang disebabkan oleh berbagai hal seperti trauma benda tajam atau tumpul, perubahan suhu, zat kimia, ledakan, sengatan listrik, atau gigitan hewan. Salah satu contoh insiden luka yang sering terjadi adalah luka sayat, yaitu adanya robekan linier pada kulit dan jaringan di bawahnya karenateriris oleh instrumen tajam, misalnya yang terjadi akibat pembedahan (Primadina dkk, 2019).
Kejadian yang tidak terduga tersebut apabila tidak di obati dengan baik dapat menyebabkan keadaan luka pada kulit menjadi lebih parah dan rentan oleh infeksi bakteri maupun jamur akibat dari masuknya kuman melalui jaringan tubuh yang rusak (Eriadi dkk, 2015).

Proses penyembuhan luka akan melalui 3 (tiga) fase yang meliputi fase inflamasi yang merupakan prioritas fungsional dimana terjadi proses hemostatis, menyingkirkan jaringan mati, dan mencegah infeksi oleh bakteri patogen. Fase kedua adalah fase proliperatif dimana keratinosit di sekitar 
luka akan mengalami perubahan fenotif beserta regenerasi jaringan dan yang terakhir adalah fase remodeling yang bertujuan untuk memaksimalkan kekuatan dan integritas struktur jaringan baru pada luka (Eriadidkk,2015).

Suatu luka dapat dikatakan sembuh secara sempurna apabila fungsi dan struktur jaringan tubuh yang terputus (rusak) telah kembali ke struktur jaringan tubuh yang normal (Primadinadkk,2019).

Indonesia dikenal sebagai salah satu Negara yang memiliki keanekaragaman hayati terbesar didunia sehingga disebut dengan julukan Megadiversity. Keanekaragaman hayati tersebut dapat dilihat dalam berbagai macam tumbuhan yang secara tradisional dapat digunakan untuk penyembuhan berbagai macam penyakit (Eriadi dkk, 2015).

Penggunaan obat tradisional tersebut merupakan salah satu alternatif untuk memenuhi kebutuhan dasar masyarakat di bidang kesehatan (Wijaya dkk, 2014).

Salah satu tumbuhan berkhasiat obat yang memiliki banyak manfaat misalnya daun bangun-bangun (Coleus amboinicus Lour). Pemanfaatan tumbuhan sebagai bahan obat pada umumnya berhubungan dengan kandungan metabolit sekundernya (Silalahi, 2018).

Hasil analisis

fitokimia memperlihatkan daun bangun-bangun (Coleus amboinicus Lour.) mengandung senyawa metabolit sekunder sepertiProses penyembuhan luka akan melalui 3 (tiga) fase yang meliputi fase inflamasi yang merupakan prioritas fungsional dimana terjadi proses hemostatis, menyingkirkan jaringan mati, dan mencegah infeksi oleh bakteri patogen. Fase kedua adalah fase proliperatif dimana keratinosit di sekitar luka akan mengalami perubahan fenotif beserta regenerasi jaringan dan yang terakhir adalah fase remodeling yang bertujuan untuk memaksimalkan kekuatan dan integritas struktur jaringan baru pada luka (Eriadidkk,2015).

Suatu luka dapat dikatakan sembuh secara sempurna apabila fungsi dan struktur jaringan tubuh yang terputus (rusak) telah kembali ke struktur jaringan tubuh yang normal (Primadinadkk,2019).

Indonesia dikenal sebagai salah satu Negara yang memiliki keanekaragaman hayati terbesar didunia sehingga disebut dengan julukan Mega diversity. Keanekaragaman hayati tersebut dapat dilihat dalam berbagai macam tumbuhan yang secara tradisional dapat digunakan untuk penyembuhan berbagai macam penyakit (Eriadi dkk, 2015).

Penggunaan obat tradisional tersebut merupakan salah satu alternatif untuk memenuhi kebutuhan dasar masyarakat di bidang kesehatan (Wijaya dkk, 2014).

Salah satu tumbuhan berkhasiat obat yang memiliki banyak manfaat misalnya daun bangun-bangun (Coleus amboinicus Lour.). Pemanfaatan tumbuhan sebagai bahan obat pada umumnya berhubungan dengan kandungan metabolit sekundernya (Silalahi, 2018).

Hasil analisis fitokimia memperlihatkan daun bangun-bangun (Coleus amboinicus Lour.) mengandung senyawa metabolit sekunder sepertiProses penyembuhan luka akan melalui 3 (tiga) fase yang meliputi fase inflamasi yang merupakan prioritas fungsional dimana terjadi proses hemostatis, menyingkirkan jaringan mati, dan mencegah infeksi oleh bakteri patogen. Fase kedua adalah fase proliperatif dimana keratinosit di sekitar luka akan mengalami perubahan fenotif beserta regenerasi jaringan dan yang terakhir adalah fase 
remodeling yang bertujuan untuk memaksimalkan kekuatan dan integritas struktur jaringan baru pada luka (Eriadidkk,2015).

Suatu luka dapat dikatakan sembuh secara sempurna apabila fungsi dan struktur jaringan tubuh yang terputus (rusak) telah kembali ke struktur jaringan tubuh yang normal (Primadinadkk, 2019).

Indonesia dikenal sebagai salah satu Negara yang memiliki keanekaragaman hayati terbesar didunia sehingga disebut dengan julukan Mega diversity. Keanekaragaman hayati tersebut dapat dilihat dalam berbagai macam tumbuhan yang secara tradisional dapat digunakan untuk penyembuhan berbagai macam penyakit (Eriadi dkk, 2015).

Penggunaan obat tradisional tersebut merupakan salah satu alternatif untuk memenuhi kebutuhan dasar masyarakat di bidang kesehatan (Wijaya dkk, 2014).

Salah satu tumbuhan berkhasiat obat yang memiliki banyak manfaat misalnya daun bangun-bangun (Coleus amboinicus Lour). Pemanfaatan tumbuhan sebagai bahan obat pada umumnya berhubungan dengan kandungan metabolit sekundernya (Silalahi, 2018).

Hasil analisis fitokimia memperlihatkan daun bangun - bangun (Coleus amboinicus Lour) mengandung senyawa metabolit sekunder seperti alkaloid, flavonoid, steroid, terpenoid, tanin, dan saponin serta kandungan minyak atsiri yang cukup tinggi.

Senyawa alkaloid, tanin, dan saponin bekerja sebagai anti mikroba dan senyawa antioksidan seperti flavonoid berperan sebagai antioksidan dalam proses penyembuhan luka sehingga daun bangun -bangun banyak digunakan dalam pengobatan gangguan kulit terutama dalam proses penyembuhan luka sayat (Lubis,2019). Tanaman kelapa sawit (Elaeis guineensis Jacq) merupakan salah satu komoditas primadona yang dikenal sebagai penghasil minyak goring di Indonesia, sementara daunnya belum digunakan secara maksimum sebagai sumber obat (Risza,1994).

Berdasarkan penelitian terdahulu, daun kelapa sawit dinyatakan tidak beracun serta dinyatakan mengandung senyawa-senyawa metabolit sekunder seperti tanin, alkaloid, saponin, steroid, terpenoid dan flavonoid. Senyawa alkaloid, tanin, dan saponin memiliki aktivitas sebagai antimikroba dan senyawa flavonoid yang memiliki aktivitas sebagai antioksidan berperan dalam proses penyembuhan luka dan direkomendasikan sebagai produk alami komersial (Sasidharan dkk, 2010).

Berdasarkan kandungan metabolit sekunder yang terkandung di dalam daun bangun-bangun (Coleus amboinicus Lour.) dan daun kelapa sawit (Elaeis guineensis Jacq.) yang berpotensi sebagai obat luka sayat, maka peneliti ingin melakukan penelitian yang berjudul "Efektivitas Salep Kombinasi Ekstrak Daun Bangun - Bangun (Coleus amboinicus Lour.) Dan Daun Kelapa Sawit (Elaeis guineensis Jacq.) Sebagai Obat LukaSayat".

\section{METODE}

Penelitian ini merupakan penelitian eksperimental, yaitu penelitian dengan melakukan percobaan terhadap kelompok yang dikenai perlakuan. Penelitian ini bertujuan untuk mengetahui penyembuhan luka sayat pada kelinci dengan perbandingan ekstrak etanol daun bangunbangun (Coleus amboinicus Lour.), ekstrak etanol daun kelapa sawit (Elaeis guineensis Jacq.), kombinasi ekstrak etanol daun 
bangun-bangun dan daun kelapa sawit serta salep betadine sebagai kontrol positif $(+)$.

Sampel yang digunakan dalam penelitian ini adalah daun bangun- bangun dan daun kelapa sawit.Sampel daun bangun-bangun dan sampel daun kelapa sawit diambil dari Desa Tiga Juhar, Kec. STM Hulu Kabupaten Deli Serdang, Provinsi Sumatera Utara. Pengambilan sampel dilakukan secara purposive yaitu teknik pengambilan sampel tanpa membandingkan dengan sampel yang sama dari daerah lain.

Pembuatan ekstrak etanol daun bangun - bangun dan ekstrak etanol daun kelapa sawit dilakukan di Laboratorium Biologi. Formulasi sediaan salep kombinasi ekstrak daun bangun-bangun dan daun kelapa sawit di lakukan di Laboratorium Teknologi Sediaan Farmasi. Pengamatan waktu penyembuhan luka sayat pada kelinci dilakukan di Laboratorium Farmakologi Fakultas Farmasi Institut Kesehatan Deli HusadaDeliTua.

Formula standar dasar salep yang digunakan (Eriadi dkk, 2015) ialah :

$\begin{array}{ll}\text { R/ Adeps Lanae } & 15 \mathrm{~g} \\ \text { Vaselin Album } & 85 \mathrm{~g} \\ \text { m.f salep } & 100 \mathrm{~g}\end{array}$

Tabel 1.Formula Sediaan Salep Ekstrak Etanol Daun Bangun-bangun dan Daun Kelapa Sawit

\begin{tabular}{c|ccccc} 
Komposisi & \multicolumn{5}{|c}{ Formula } \\
\cline { 1 - 5 } Ekstrak & F1 & F2 & F3 & F4 & F5 \\
\cline { 2 - 6 }$(\mathbf{g})$ Dasar & - & - & 10 & 10 & 20 \\
& - & 100 & 90 & 90 & 80 \\
\cline { 1 - 1 } $\begin{array}{c}\text { salep (g) } \\
\text { Kontrol }\end{array}$ & 100 & - & - & - & - \\
\hline
\end{tabular}

\section{positif(g)}

F5 : Formula 5 salep kombinasi EEDB $10 \%+$ EEDKS $10 \%$.

Ditimbang semua bahan yang akan digunakan dalam pembuatan sediaan salep. Pada lumpang, dimasukkan Adeps Lanae dan Vaseline Album lalu digerus sampai homogen hingga terbentuk basis salep.Ekstrak ditambahkan sedikit demi sedikit ke dalam lumpang yang berisi dasar salep lalu digerus hingga homogen.Salep dimasukkan ke dalam wadah dan ditutup rapat, kemudian disimpan ditempat yang terlindung dari cahaya (Effendi dkk, 2015).

Hewan uji yang digunakan dalam penelitian ini adalah kelinci jantan sebanyak 5 ekor yang dikarantina selama 7 hari sebelum penelitian, bertujuan agar hewan uji terbiasa dengan lingkungan dan perlakuan yang baru yang ditempatkan dalam kandang dan diberi makan yang cukup setiap harinya.

Sebelum perlakuan, kelinci dikelompokkan dalam 5 kelompok perlakuan:

a. Kelompok I : Sebagaipembanding positif diberikan salep Betadine ${ }^{\circledR}$

b. Kelompok II : Sebagai kontrol negative diberikan Basis salep

c. Kelompok III: Diberikansalep EEDB $10 \%$

d. Kelompok IV : Diberikan salep EEDKS $10 \%$

e. Kelompok V : Diberikan salep kombinasi EEDB 10\% + EEDKS $10 \%$.

Masing-masing kelinci dicukur pada bagian punggungnya kemudian dibersihkan dengan alkohol 70\%. Selanjutnya kelinci di anestesi dengan menggunakan Lidocain $\mathrm{HCL}$ $2 \%$ sebanyak $0,5 \mathrm{ml}$ secara subkutan. Selanjutnya dibuat tanda di bagian yang akan dilukai dengan diameter $2 \mathrm{~cm}$, dengan cara mengangkat kulit kelinci menggunakan pinset kemudian dibuat luka menggunakangunting bedah yang sudah 
disterilkan terlebih dahulu dengan alkohol $70 \%$. Pada kulit yang mengalami luka sayat tersebut diberi perlakuan sebagai berikut:

a. Kelompok I : Dioleskan Salep Betadine ${ }^{\circ}$ secara merata kepermukaan kulit yang luka satu kali sehari.

b. Kelompok II : Dioleskan basissalep secara merata ke permukaan kulit yang luka satu kali sehari.

c. Kelompok III : DioleskansalepEEDB $10 \%$ secara merat kepermukaan kulit yang luka satu kali sehari

d. Kelompok IV : DioleskansalepEEDKS $10 \%$ secaramerata kepermukaan kulit yang luka satu kali sehari

e. Kelompok V : Dioleskan salep

ekstrak kombinasi EEDB 10\% +EEDKS $10 \%$ secara merata kepermukaan kulit yang luka satu kali sehari.

Diukur diameter luka dimulai hari pertama dengan jangka sorong. Pengukuran dilakukan setiap hari dimulai dari hari pertama sampai luka dinyatakan sembuh. Luka dikatakan sembuh apabila diameter luka mencapai $0 \mathrm{~cm}$.

\section{HASIL}

Pada penelitian ini dilakukan kembali uji skrinning fitokimia pada serbuk simplisia daun bangun-bangun dan daun kelapa sawit. Hasil uji skrinning fitokimia pada penelitian ini dapat dilihat pada tabel2.

Tabel 2. Hasil skrining fitokimia

\begin{tabular}{|c|c|c|c|}
\hline No & Pemeriksaan & $\begin{array}{c}\text { Daun } \\
\text { Bangun- } \\
\text { Bangun }\end{array}$ & $\begin{array}{c}\text { Daun } \\
\text { kelapa } \\
\text { Sawit }\end{array}$ \\
\hline 1 & Tanin & + & + \\
\hline
\end{tabular}

\begin{tabular}{|c|c|c|c|}
\hline 2 & Flavonoid & + & + \\
\hline 3 & Alkaloid & + & + \\
\hline
\end{tabular}

Hasil uji skrinning fitokimia daun kelapa sawit menunjukkan daun kelapa sawit positif mengandung metabolit sekunder tanin, alkaloid, dan flavonoid.

Sebelum dilakukan uji efektifitas salep kombinasi EEDB dan EEDKS terhadap penyembuhan luka sayat, terlebih dahulu daun-daun tersebut dikarakterisasi, hasil karakterisasi dapat dilihat pada Tabel3.

Tabel 3. Hasil Karakterisasi Simplisia

\begin{tabular}{|c|c|c|}
\hline Parameter & $\begin{array}{c}\text { Daun } \\
\text { Bangun- } \\
\text { Bangun }\end{array}$ & $\begin{array}{c}\text { Daun } \\
\text { Kelapa } \\
\text { Sawit }\end{array}$ \\
\hline Kadar Air & $8.3 \%$ & $6.2 \%$ \\
\hline Kadar Debu & $3.79 \%$ & $4.28 \%$ \\
\hline
\end{tabular}

kadar abu total dilakukan untuk mengetahui kadar senyawa anorganik dalam simplisia, misalnya logam $\mathrm{K}, \mathrm{Ca}, \mathrm{Na}$, $\mathrm{Pb}$ danHg.

Pemeriksaan organoleptis sediaan salep meliputi pemeriksaan warna, bau, bentuk sediaan dan homogenitas sediaan.

Tabel 4. Pemeriksaan Organoleptis Sediaan Salep

\begin{tabular}{|c|c|c|c|c|}
\hline & \multicolumn{4}{|c|}{ Pemeriksaan organoleptis } \\
\hline & $\begin{array}{c}\text { War } \\
\text { na }\end{array}$ & Bau & $\begin{array}{l}\text { Bentuk } \\
\text { sediaan }\end{array}$ & $\begin{array}{c}\text { Homoge } \\
\text { nitas }\end{array}$ \\
\hline $\mathbf{F 1}$ & $\begin{array}{l}\text { Putih } \\
\text { keku } \\
\text { ning } \\
\text { an }\end{array}$ & $\begin{array}{l}\text { Bau } \\
\text { khas }\end{array}$ & $\begin{array}{c}\text { Setengah } \\
\text { padat }\end{array}$ & Homogen \\
\hline F2 & $\begin{array}{c}\text { Hijau } \\
\text { kehit } \\
\text { ama } \\
\text { n }\end{array}$ & $\begin{array}{l}\text { Bau } \\
\text { khas }\end{array}$ & $\begin{array}{c}\text { Setengah } \\
\text { padat }\end{array}$ & Homogen \\
\hline F3 & $\begin{array}{c}\text { Hijau } \\
\text { kehit } \\
\text { ama } \\
\text { n }\end{array}$ & $\begin{array}{l}\text { Bau } \\
\text { khas }\end{array}$ & $\begin{array}{c}\text { Setengah } \\
\text { padat }\end{array}$ & Homogen \\
\hline $\mathbf{F 4}$ & $\begin{array}{l}\text { Hijau } \\
\text { kehit }\end{array}$ & $\begin{array}{l}\text { Bau } \\
\text { khas }\end{array}$ & $\begin{array}{c}\text { Setengah } \\
\text { padat }\end{array}$ & Homogen \\
\hline
\end{tabular}

Berdasarkan tabel diatas, dapat 
diketahui bahwa sediaan salep berwarna hijau kehitaman mengikuti warna ekstrak dari EEDB dan EEDKS, berbau khas ekstrak daun, berbentuk setengah padatdanhomogen.

Pemeriksaan stabilitas fisik sediaan salep dilakukan secara visual pada suhu kamar selama 14 hari dengan dengan rentang waktu pemeriksaan 7 hari.

Tabel 5.Data stabilitas sediaan salep

\begin{tabular}{|c|c|c|c|c|}
\hline \multirow[t]{2}{*}{$\begin{array}{c}\text { Pengam } \\
\text { atan }\end{array}$} & \multirow[t]{2}{*}{ Sediaan } & \multicolumn{3}{|c|}{$\begin{array}{c}\text { Lama } \\
\text { Pengamatan } \\
\text { (Hari) }\end{array}$} \\
\hline & & H-O & $\mathrm{H}-7$ & H-14 \\
\hline \multirow{4}{*}{ Bentuk } & F1 & SP & SP & SP \\
\hline & F2 & SP & SP & SP \\
\hline & F3 & SP & SP & SP \\
\hline & F4 & SP & SP & SP \\
\hline \multirow[t]{4}{*}{ Warna } & $\mathrm{F} 1$ & PK & PK & PK \\
\hline & $\mathrm{F} 2$ & $\mathrm{HK}$ & $\mathrm{HK}$ & HK-an \\
\hline & F3 & $\mathrm{HK}$ & $\mathrm{HK}$ & $\mathrm{HK}$ \\
\hline & F4 & $\mathrm{HK}$ & HK & HK-an \\
\hline \multirow[t]{4}{*}{ Bau } & F1 & $\mathrm{BK}$ & $\mathrm{BK}$ & BK Ko \\
\hline & F2 & $\mathrm{BK}$ & $\mathrm{BK}$ & BK ari \\
\hline & F3 & $\mathrm{BK}$ & $\mathrm{BK}$ & $\mathrm{BK}$ a \\
\hline & $\mathrm{F} 4$ & $\mathrm{BK}$ & BK & $\mathrm{BK}$ \\
\hline
\end{tabular}

Tabel 6.Data penurunan diameter luka

\begin{tabular}{|c|c|c|c|c|c|}
\hline \multirow{2}{*}{} & \multicolumn{5}{|c|}{ Diameter Iuka (cm) } \\
\cline { 2 - 6 } & $\mathbf{K 1}$ & $\mathbf{K 2}$ & $\mathbf{K 3}$ & $\mathbf{K 4}$ & $\mathbf{K 5}$ \\
\hline 0 & 2,00 & 2,00 & 2,00 & 2,00 & 2,00 \\
\hline 1 & 1,98 & 2,00 & 1,98 & 1,98 & 2,00 \\
\hline 2 & 1,95 & 2,00 & 1,96 & 1,95 & 1,98 \\
\hline 3 & 1,85 & 1,98 & 1,92 & 1,90 & 1,96 \\
\hline 4 & 1,80 & 1,95 & 1,88 & 1,85 & 1,90 \\
\hline 5 & 1,72 & 1,90 & 1,82 & 1,80 & 1,85 \\
\hline 6 & 1,65 & 1,85 & 1,75 & 1,72 & 1,80 \\
\hline 7 & 1,52 & 1,80 & 1,67 & 1,65 & 1,72 \\
\hline 8 & 1,45 & 1,72 & 1,55 & 1,53 & 1,65 \\
\hline 9 & 1,32 & 1,65 & 1,47 & 1,45 & 1,55 \\
\hline 10 & 1,25 & 1,55 & 1,35 & 1,32 & 1,45 \\
\hline 11 & 1,15 & 1,45 & 1,25 & 1,20 & 1,35 \\
\hline 12 & 0,95 & 1,35 & 1,10 & 1,05 & 1,22 \\
\hline 13 & 0,85 & 1,22 & 0,90 & 0,88 & 1,15 \\
\hline
\end{tabular}

\begin{tabular}{|c|c|c|c|c|c|}
\hline 14 & 0,68 & 1,15 & 0,75 & 0,72 & 0,95 \\
\hline 15 & 0,55 & 0,95 & 0,65 & 0,62 & 0,85 \\
\hline 16 & 0,38 & 0,85 & 0,55 & 0,52 & 0,75 \\
\hline 17 & 0,25 & 0,72 & 0,45 & 0,42 & 0,65 \\
\hline 18 & 0 & 0,65 & 0,35 & 0,32 & 0,55 \\
\hline 19 & 0 & 0,55 & 0,25 & 0,22 & 0,45 \\
\hline 20 & 0 & 0,45 & 0 & 0 & 0,35 \\
\hline 21 & 0 & 0,35 & 0 & 0 & 0,25 \\
\hline 22 & 0 & 0,25 & 0 & 0 & 0 \\
\hline 23 & 0 & 0 & 0 & 0 & 0 \\
\hline
\end{tabular}

\section{PEMBAHASAN}

Pada penelitian ini dilakukan uji skrinning fitokimia tehadap daun bangunbangu dan daun kelapa sawit dengan tujuan melihat kandungan senyawa metabolit sekundernya.Pada pemeriksaan skirining alkaloid dengan penambahan pereaksi Mayer terbentuk endapan putih, Bourchardat terbentuk endapan berwarna coklat kemerahan dan dengan Dragendroff terbentuk endapan berwarna jingga.Penambahan serbuk $\mathrm{Mg}$ dan asam klorida pekat menghasilkan larutan berwarna merah dan penambahan amil alkohol terbentuk warna merah yang menunjukkan adanya flavonoid. Penambahan $\mathrm{FeCl} 3$ memberikan warna biru kehitaman yang menunjukkan adanyasenyawatanin.

Hasil uji skrinning fitokimia daun kelapa sawit menunjukkan daun bangunbangun dan daun kelapa sawit positif mengandung metabolit sekunder tanin, alkaloid, dan flavonoid.

\section{Telah dilakukan pemeriksaan} karakterisasi penetapan kadar air dan terlihat bahwa kadar air simplisia adalah 8,3 $\%$ menunjukkan bahwa simplisia memenuhi persyaratan umum yaitu di bawah $10 \%$. Penetapan kadar air dilakukan karena air merupakan media yang baik untuk tumbuhnya jamur. 
Penetapan kadar abu total dilakukan untuk mengetahui kadar senyawa anorganik dalam simplisia, misalnya logam $\mathrm{K}, \mathrm{Ca}, \mathrm{Na}, \mathrm{Pb}$ dan $\mathrm{Hg}$. Kadar abu total pada simplisia daun bangun-bangun adalah 3,79\%, menunjukkan bahwa simplisia memenuhi persyaratan umum yaitu $<8,2 \%$.

Pada pemeriksaan karakterisasi penetapan kadar air dan terlihat bahwa kadar air simplisia adalah 6,2 \% menunjukkan bahwa simplisia memenuhi persyaratan umum yaitu di bawah $10 \%$. Penetapan kadar air perlu dilakukan karena air merupakan media yang baik untuk tumbuhnya jamur.

Penetapan kadar abu total dilakukan untuk mengetahui kadar senyawa anorganik dalam simplisia, misalnya logam $\mathrm{K}, \mathrm{Ca}, \mathrm{Na}, \mathrm{Pb}$ dan $\mathrm{Hg}$. Kadar abu total pada simplisia daun bangun-bangun adalah 4,28 \%, menunjukkan bahwa simplisia memenuhi persyaratan umum yaitu $<8,2 \%$.

Hasil pemeriksaan organoleptis sediaan salep berkaitan dengan pemeriksaan warna, bau, dan bentuk sediaan. Warna yang dihasilkan pada sedian formulasi II, III, dan IV hampir sama yaitu hijau kehitaman dengan kepekatan yang berbeda-beda. Formula II dengan penambahan EEDB $10 \%$ berwarna hijau kehitaman terang. Formula III dengan penambahan EEDKS 10\% berwarna hijau kehitaman pekat. Formula IV dengan penambahan EEDB $10 \%+$ EEDKS $10 \%$ berwarna hijau kehitaman yang paling pekat.

Bau atau aroma yang dihasilkan dari sediaan salep adalah bau khas dari ekstrak daun yang digunakan dalam pembuatan salep yaitu daun bangun - bangun dan daun kelapa sawit.Salep yang dihasilkan tidak berbau tengik dan berbentuk setengah padat. Hasil pengamatan homogenitas dari semua sediaan salep adalah homogen. Uji homogenitas bertujuan untuk melihat dan mengetahui bahan bahan sediaan salep apakah tercampur secaramerata.

Dari hasil uji stabilitas salep EEDB $10 \%$, EEDKS $10 \%$ dan salep kombinasi EEDB $10 \%+$ EEDKS $10 \%$ mempunyai bentuk, warna dan bau sediaan yang stabil. Suatu sediaan memiliki bentuk yang baik jika selama proses penyimpanan tidak terjadi bleeding yaitu terjadinya pemisahan antara basis salep dengan ekstrak yang dapat terjadi karena basis salep dan ekstrak tidak tercampur sempurna.

Gambar 1. Formulasi sediaan salep

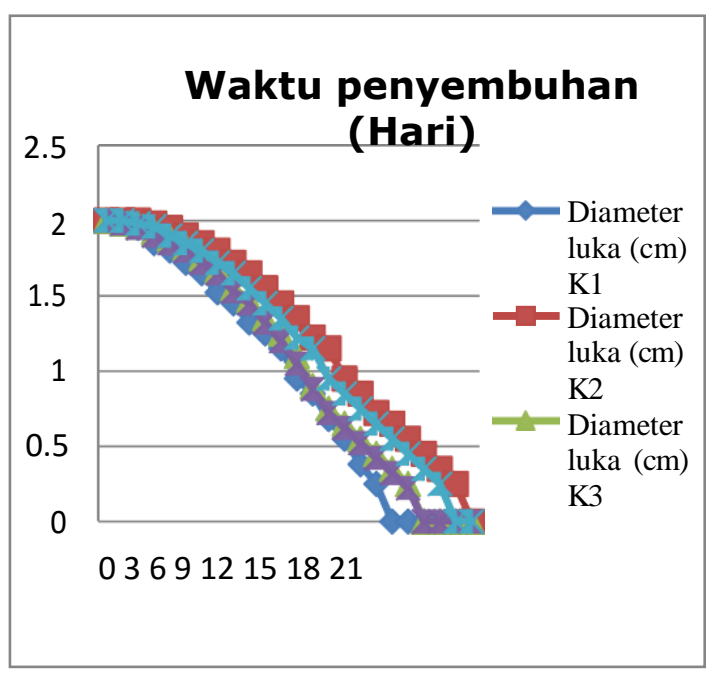

Semua kelompok perlakuan mengalami pengurangan diameter luka sayat yang berangsur sembuh. Luka dinyatakan sembuh apabila diameter luka adalah $0 \mathrm{~cm}$ dan tidak menimbulkan bekas pada kulit (Hasibuan,2014). Adanya perbedaan penyembuhan diameter luka pada masingmasing kelinci karena adanya faktor psikologis atau variabel individu yang dapat menurunkan efisiensi kerja sistem imun tubuh dalam proses penyembuhan luka (Hasibuan,2014).

Pada betadine salep, pengurangan 
diameter luka sayat pada hari ke-1 sebesar $(0,02 \mathrm{~cm})$ dan pada hari ke-18 (0 $\mathrm{cm}$ ). Betadine mengandung bahan aktif povidone iodine yang mampu menyembuhkan infeksi luka di kulit yang disebabkan oleh bakteri gram positif dannegatif (Hasibuan,2014).

Ketiga dosis sediaan salep EEDB $10 \%$, EEDKS $10 \%$ dan kombinasi EEDB $10 \%+$ EEDKS $10 \%$ dapat menyembuhkan luka sayat, dimana pada sediaan salep EEDB $10 \%$ pengurangan diameter luka dimulai pada hari ke-1 $(0,02$ $\mathrm{cm})$ dan hari ke-20 (0 cm) sembuh. Sediaan salep EEDKS $10 \%$ pengurangan diameter luka pada hari ke-1 $(0,02 \mathrm{~cm})$ dan hari ke-20 $(0 \mathrm{~cm})$ sembuh. Sediaan salep EEDB $10 \%+$ EEDKS $10 \%$ pengurangan diameter luka terjadi pada hari ke-2 $(0,02 \mathrm{~cm})$ dan hari ke-22(0cm).

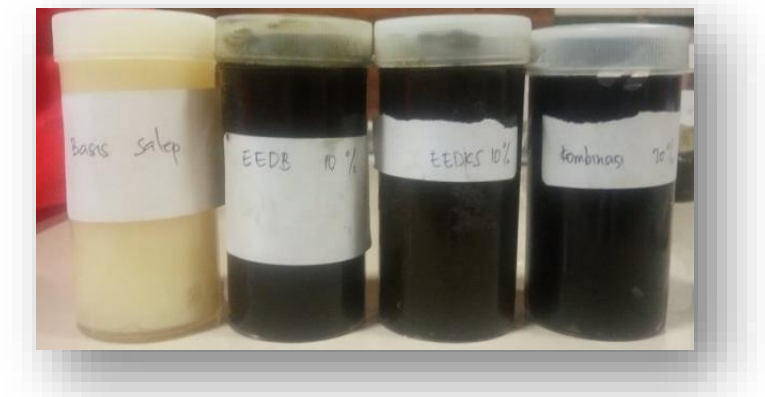

Pada basis salep pengurangan diameter luka dimulai pada hari ke-3 $(0,02$ $\mathrm{cm})$ dan hari ke-23 $(0 \mathrm{~cm})$. Pengurangan diameter luka berangsur lambat karena tidak ada zat berkhasiat dalam basis salep yang digunakan sebagai bahan pembawa.

Efektivitas penyembuhan luka sayat dari sediaan salep EEDB 10\%, EEDKS 10\% dan kombinasi EEDB 10\% + EEDKS 10\% karena adanya kandungan alkaloid yang memiliki kemampuan sebagai antibakteri, flavonoid memiliki aktivitas antimikroba dan astringen, yang memiliki peran dalam penyusutan luka dan peningkatan laju epitelisasi, tanin sebagai astringen yang mampu menciutkan luka, menghentikan pendarahan dan mengurangi peradangan (Hasibuan,2014).

Berdasarkan hasil pengujian penyembuhan luka sayat yang memiliki daya efektivitas paling baik berturut- turut adalah betadine salep sebagai pembanding, sebagai ekstrak uji yaitu sediaan salep EEDKS $10 \%$, EEDB $10 \%$, kombinasi EEDB $10 \%+$ EEDKS 10\%, dan basis salep. Sediaan salep EEDB $10 \%$ dan EEDKS $10 \%$ dosis sudah tepat untuk menyembuhkan luka sayat yang sudah sebanding dengan obat pembanding, sedangkan pada sediaan salep kombinasi EEDB $10 \%+$ EEDKS $10 \%$ kesembuhanluka sayat lebih lama karena tidak selamanya semakin tinggi dosis maka semakin tinggi juga efek farmakologi yang di hasilkan, hal ini menunjukkan bahwa efek farmakologi obatakan jenuh pada konsentrasitertentu.

\section{KESIMPULAN}

Berdasarkan hasil penelitian dapat disimpulkan bahwa semua kelompok memberikan efek penyembuhan luka sayat dan kelompok yang paling efektif dalam menyembuhkan luka sayat adalah kelompok 4 dengan perlakuan menggunakan salepEEDKS10\%.

\section{DAFTAR PUSTAKA}

Effendi, F. Halimatussa'diyah, dan Sri,H. (2015).

Efektivita

s Penyembuhan Luka Terbuka Pada Kelinci Dari Formulasi Salep Ekstrak Etanol Daun Babadotan (Ageratu

$m$ conyzoides L.). Bogor : Jurnal Farmasi Sekolah Tinggi Teknologi Industri dan Farmasi Bogor : Halaman4-8. 
Eriadi, Aried, dkk. (2015). Pengaruh Ekstrak Etanol Daun Bonginah (Anredera

cordifolia (Tenore) Steen) Terhadap Penyembuhan Luka Sayat Pada Tikus Putih Jantan. Padang: Jurnal Fakultas Farmasi Universitas Andalas Higea, Vol. 7, No. 2: Halaman162,164, 170.

Hasibuan, C., S. (2014). Skrining Fitokimia dan Uji Efektivitas Sediaan Gel Ekstrak Etanol Daun Kelapa Sawit (Elaeis guineensis Jacq.) Terhadap Penyembuhan Luka Sayat. Skripsi. Medan: Fakultas Farmasi Universitas Sumatera Utara.

Lubis, Rosliana. (2019). Skrining Fitokimia Dan Aktivitas Antimikroba Dari Tumbuhan Bangun - Bangun (Coleus Amboinicus Lour.). Medan: Talenta. Volume 2 Nomor1: Halaman95.

Primadina, N., Achmad, B., dan David, S., P. (2019). Proses Penyembuhan Luka Ditinjau Dari Aspek Mekanisme Seluler Dan Molekuler. Surabaya: Qanun Medika Vol.3 No.1: Halaman 32- 38.

Risza, Suyatno. (1994). Seri Budidaya Kelapa Sawit Upaya Peningkatan Produktivitas. Yogyakarta: Penerbit Kanisius. Halaman 39- 40.

Sasidharan, Sreenivasan, dkk. (2010). Wound Healing Potential of Elaeis guineensis Jacq Leaves in an Infected Albino Rat Model. Malaysia: Molecules, Volume 15: Halaman31883189.

Silalahi, Marina. (2018). Plectranthus Amboinicus (Lour.)Spreng SebagaiBahan Pangan Dan Obat SertaBioaktivitasnya. Jakarta: JDP Volume 11, Nomor 2: Halaman 123138.
Wijaya B., A., Gayatri C., dan Frenly W. (2014). Potensi Ekatrak Etanol Tangkai Daun Talas (Colocasia esculenta (L.)) Sebagai Alternatif Obat Luka Pada Kulit Kelinci (Oryctolagus cuniculus). Manado: Pharmacon Jurnal IImiah Farmasi Volume, 3 No. 3: Halaman 212 